\title{
Incentivizing health care behaviors in emerging adults: a systematic review
}

\author{
This article was published in the following Dove Press journal: \\ Patient Preference and Adherence \\ 24 March 2016 \\ Number of times this article has been viewed
}

\author{
Catherine $\mathrm{HYu}^{1,2}$ \\ Giuliana Guarna' \\ Pamela Tsao ${ }^{3}$ \\ Jude R Jesuthasan' \\ Adrian NC $\mathrm{Lau}^{3,4}$ \\ Ferhan S Siddiqi' \\ Julie Anne Gilmour ${ }^{3}$ \\ Danyal Ladha' \\ Henry Halapy ${ }^{5}$ \\ Andrew Advani ${ }^{1-3}$ \\ 'Li Ka Shing Knowledge Institute, \\ St Michael's Hospital, ${ }^{2}$ Division of \\ Endocrinology and Metabolism, \\ Department of Medicine, St Michael's \\ Hospital, University of Toronto, \\ ${ }^{3}$ Department of Medicine, Faculty \\ of Medicine, University of Toronto, \\ ${ }^{4}$ Division of Endocrinology, \\ Department of Medicine, University \\ Health Network, ${ }^{5}$ Leslie Dan Faculty \\ of Pharmacy, University of Toronto, \\ Toronto, ON, Canada
}

Purpose: For emerging adults with chronic medical diseases, the transition from pediatric to adult health care is often a time of great upheaval, commonly associated with unhealthy selfmanagement choices, loss to follow-up, and adverse outcomes. We conducted a systematic review to examine the use of incentive strategies to promote positive health-related behaviors in young adults with chronic medical diseases.

Methods: The Medline, CINAHL, Embase, PsycInfo, and Cochrane databases were searched through June 2014. Studies of any design where an incentive was used to achieve a target behavior or outcome in a pediatric or emerging adult population (age $<30$ years) with chronic medical conditions including addictions, were included.

Results: A total of 26 studies comprising 10,880 patients met our inclusion criteria after screening 10,305 abstracts and 301 full-text articles. Of these studies, 20 examined the effects of behavioral incentives on cigarette smoking or substance abuse, including alcohol; four studies explored behavioral incentives in the setting of HIV or sexual health; and two articles studied individuals with other chronic medical conditions. Seventeen articles reported a statistically significant benefit of the behavioral incentive on one or more outcomes, although only half reported follow-up after the incentive period was terminated.

Conclusion: While the majority of studies reported positive outcomes, these studies focused on promoting the cessation of adverse behaviors rather than promoting positive behaviors. In addition, conclusions were limited by the high risk of bias present in the majority of studies, as well as lack of follow-up after the incentive period. Whether behavioral incentives facilitate the adoption of positive health choices in this population remains to be determined.

Keywords: incentive, young adult, transition, self-management

\section{Introduction}

The term "emerging adulthood" has been coined to describe the period of life approximately between the ages of 18 and 30 years when an individual separates from parental care and assumes responsibility for his or her own choices. ${ }^{1}$ Broadly speaking, this developmental period consists of two stages: an early phase ( $\sim 18-24$ years) reflecting the first few years after high school and a later phase ( $25-30$ years $)$ with the adoption of more traditional adult roles. ${ }^{1}$ At this time of life, an emerging adult with a special health-related need (eg, diabetes, cystic fibrosis, organ transplantation, or a previous cancer diagnosis) faces all of the upheaval that may be experienced by his or her peers, compounded by the added burden of the chronic medical condition. The young person must navigate the often-foreboding chasm between pediatric and adult health care systems and simultaneously master self-care behavior skills in the face of competing peer-group influences. While the increased risk of adverse health outcomes during this
Correspondence: Catherine $\mathrm{H}$ Yu Li Ka Shing Knowledge Institute, St Michael's Hospital, 30 Bond Street. Toronto, ON M5B IW8, Canada

$\mathrm{Tel}+\mathrm{I} 4168646060$

Fax +I 4168673679

Email yuca@smh.ca (c) (1) (5) 2016 Yu et al. This work is published and licensed by Dove Medical Press Limited. The full terms of this license are available at https://www.dovepress.com/terms.php cc) ${ }_{\mathrm{BY}} \mathrm{NC}$ and incorporate the Creative Commons Attribution - Non Commercial (unported, v3.0) License (http://creativecommons.org/licenses/by-n/3.0/). By accessing the work you hereby accept the Terms. Non-commercial uses of the work are permitted without any further permission from Dove Medical Press Limited, provided the work is properly attributed. For permission hereby accept the Terms. Non-commercial uses of the work are permitted without any further permission from Dove Mercial use of this work, please see paragraphs 4.2 and 5 of our Terms (https://www.doveperss.com/terms.php).
for commercial 
vulnerable transition period is well recognized, there is a paucity of evidence supporting any specific strategy directed at smoothing the process. ${ }^{2}$

Several approaches have been trialed in an attempt to address these challenges, directed at a system (eg, transition clinics), staff (eg, transition coordinator), or individual (eg, peer-mentoring) level. ${ }^{3}$ However, the results of these approaches have been mixed. ${ }^{2}$ A systematic review of interventions designed to improve transition identified ten studies, of which four were controlled clinical trials, with study arms comprising 30-153 patients. A variety of interventions were studied, including separate young adult clinics, joint pediatric/adult clinics, and diseasespecific education. Outcomes examined were primarily disease-specific clinical outcomes (eg, difference in glycemic control). These interventions demonstrated mixed effectiveness, with two of these four trials demonstrating an improvement in glycemic control in young people with diabetes. $^{2}$

One strategy to encourage positive health-related choices is the use of incentives: motivating rewards provided contingently on behavioral performance. ${ }^{4}$ The provision of behavioral incentives attempts to bridge the gap between what we actually do (first-order desires) and what we would like to do (second-order desires). ${ }^{5}$ Such an approach may be especially appealing to the transitioning population, where the obstacles of complex health care structures and competing societal demands are compounded by an intrinsic imbalance in the relative development of the limbic system (early) and prefrontal cortex (later) that favors immediate reward processing over long-term rational decision making. ${ }^{6}$

In such areas as addiction medicine, behavioral incentives have been employed and studied for decades. For example, in 2006 Prendergast et al conducted a meta-analysis of contingency-management (CM) interventions for treatment of substance abuse and identified 75 studies, demonstrating a positive effect size $(d=0.42){ }^{7}$ More recently, Cahill et al updated their systematic review of incentives for smoking cessation, identifying 21 studies examining such incentives as lottery tickets, cash payments, and vouchers, and found an odds ratio for quitting of 1.42 (95\% confidence interval 1.19-1.69). ${ }^{8}$

However, whether the same strategies can be extrapolated to promote positive health-related behaviors that exceed the societal norm for the peer group (eg, adherence to long-term medical therapy) is uncertain. Similarly, the effectiveness of incentive strategies specifically within the emerging adult population is unclear. Accordingly, we set out to conduct a systematic review of the use of incentive strategies in young adults with chronic medical diseases.

\section{Methods}

We followed the Preferred Reporting Items for Systematic review and Meta-Analysis guidelines. ${ }^{9}$

\section{Eligibility criteria}

We included studies that investigated an incentive used to achieve a target behavior or outcome in a pediatric or emerging adult population with chronic medical conditions, including addictions. We included studies of experimental (randomized controlled trials, controlled clinical trials) and observational (case-control, cohort, cross-sectional) design. We adopted Michie et al's definition of an incentive as a motivating reward provided contingently on behavioral performance, ${ }^{4}$ and included cash payments, vouchers, and lotteries with or without CM (Table 1). We defined the emerging adult population as individuals aged $18-30$ years. ${ }^{1}$ We defined chronic disease as a condition of long duration or frequent recurrence that met the following criteria: 1) an impairment of the normal functioning of some aspect of the body, 2) characteristic signs or symptoms, and 3) harm or morbidity. ${ }^{10}$ We applied this definition to a compendium of pediatric conditions, ${ }^{11}$ and from this we generated a list of chronic diseases. Substance-use disorders, such as smoking, were included, as they met the aforementioned criteria. ${ }^{12}$ The American Psychiatric Association diagnostic criteria for substance-use disorders can be categorized into impaired control (resulting in recurrent use), tolerance and withdrawal, social impairment, and risky use. ${ }^{13}$ We did not include obesity, as our initial search was conducted prior to this condition being considered a disease by the American Medical Association. ${ }^{10}$ Studies were included regardless of design, duration of follow-up, or language of publication.

\section{Information sources and literature search}

The Medline, CINAHL, Embase, PsycInfo, and Cochrane databases were searched from inception until June 2014. Reference lists of included studies and relevant reviews were also reviewed. Searches were performed with no year or language restrictions, and used combinations of the search terms "incentives", "rewards", "chronic disease", and "youth and child", as well as search terms for specific chronic diseases. Appropriate wildcards were used in the search in order to account for plurals and variations in 
Table I Types of incentives and their definition

\begin{tabular}{|c|c|c|}
\hline Incentive type & Definition & Example \\
\hline Cash payment & Direct payments of money in the form of cash & $\begin{array}{l}\text { Cash given to participants to attend a smoking- } \\
\text { cessation session }{ }^{14}\end{array}$ \\
\hline Voucher & $\begin{array}{l}\text { A form or check indicating a credit against } \\
\text { future purchases or expenditures }\end{array}$ & $\begin{array}{l}\text { Voucher for HPV-vaccine doses, }{ }^{15} \text { goods } \\
\text { purchased by study staff } 16\end{array}$ \\
\hline Lottery & $\begin{array}{l}\text { Drawing of lots in which prizes are distributed } \\
\text { to the winners among persons buying a chance }\end{array}$ & $\begin{array}{l}\text { Participants receive chits to draw for items in a } \\
\text { prize bowl, such as phone cards, iTunes vouchers, } \\
\text { skateboards, jewelry, etc }{ }^{17}\end{array}$ \\
\hline Deposit contract & $\begin{array}{l}\text { Participants put their own money at risk, } \\
\text { which can be recouped if designated } \\
\text { contingencies are met, but lost if target } \\
\text { outcome is not met }\end{array}$ & $\begin{array}{l}\text { Participant contributes } 0-\$ 3 \text { per day of their own } \\
\text { funds to a deposit contract each day; if goal met, } \\
\text { participant accumulates a reward equal to the } \\
\text { daily deposit, plus } 1: 1 \text { match from the investigator; } \\
\text { if goal not met, deposit contract money is } \\
\text { forfeited }{ }^{18}\end{array}$ \\
\hline \multicolumn{3}{|c|}{ The incentive can be further characterized by } \\
\hline Contingency management & $\begin{array}{l}\text { Receipt of the incentive is contingent on } \\
\text { achieving an outcome }\end{array}$ & $\begin{array}{l}\text { Payment received if girl attended school } 80 \% \\
\text { of days }{ }^{19}\end{array}$ \\
\hline Escalating schedule & $\begin{array}{l}\text { With each consecutive desired outcome, } \\
\text { the incentive value is increased }\end{array}$ & $\begin{array}{l}\text { With each negative carbon monoxide breath } \\
\text { sample, incentive value is increased }{ }^{14}\end{array}$ \\
\hline Reset of escalating schedule & $\begin{array}{l}\text { Escalating schedule of incentive can be reset } \\
\text { if desired outcome not met }\end{array}$ & $\begin{array}{l}\text { Incentive value reset to lowest value if positive } \\
\text { carbon monoxide breath sample }{ }^{14}\end{array}$ \\
\hline
\end{tabular}

Abbreviation: HPV, human papilloma virus.

spelling. The search strategy was drafted and conducted by an information specialist.

\section{Study selection process}

We created a study manual detailing criteria for study selection. After completing a calibration exercise, two team members independently screened each abstract for inclusion; conflicts were resolved by discussion or by a third team member. Following selection of abstracts, two team members independently reviewed each full-text article for inclusion; conflicts were similarly resolved.

\section{Data items and data collection process}

We created a study manual and a data abstraction sheet detailing data items to be collected, and a calibration exercise was conducted (data abstraction manual and sheet are available upon request). We then abstracted the following data: study characteristics (design, country, setting), target population (chronic disease, sex, age, number), behavior incentivized, incentive intervention (type, value, nature, behavioral technique), duration (run-in period, period with incentive, follow-up period), cointervention, and outcomes (disease-specific behavioral outcome, eg, adherence, avoidance, and attendance, and disease-specific clinical outcome eg, carbon monoxide levels). Each full-text article was abstracted independently by two team members; conflicts were resolved by discussion or by a third team member.

\section{Risk-of-bias assessment}

For each study type (randomized controlled trial, controlled clinical trial, cohort, case-control, and cross-sectional), we abstracted relevant study characteristics to assess the risk of bias. Specifically, we adapted the Cochrane Collaboration's tool for assessing risk of bias $^{20}$ to the study designs that we included.

\section{Synthesis}

We reported our results by descriptively summarizing literaturesearch results, types of studies, study quality and risk of bias, characteristics of target population and behaviors incentivized, follow-up, incentive characteristics, and outcome results. Metaanalyses by intervention type or disease outcomes were not possible, because of the heterogeneity of the disease states.

\section{Results}

\section{Literature search}

Medline, Embase, PsycInfo, CINAHL, and the Cochrane Central Register of Controlled Trials were searched on June 12-13, 2013 and retrieved 3,401, 3,288, 1,329, 3,414, and 169 studies, respectively. An update on the search was done on May 16, 2014, retrieving 352, 538, 180, 129, and 37 studies, respectively. A total of 29 full-text articles fulfilled the eligibility criteria. Three of the 29 articles were companion reports ${ }^{21-23}$ of two primary publications. ${ }^{15,16} \mathrm{We}$ report on the 26 primary publications (Figure 1). 

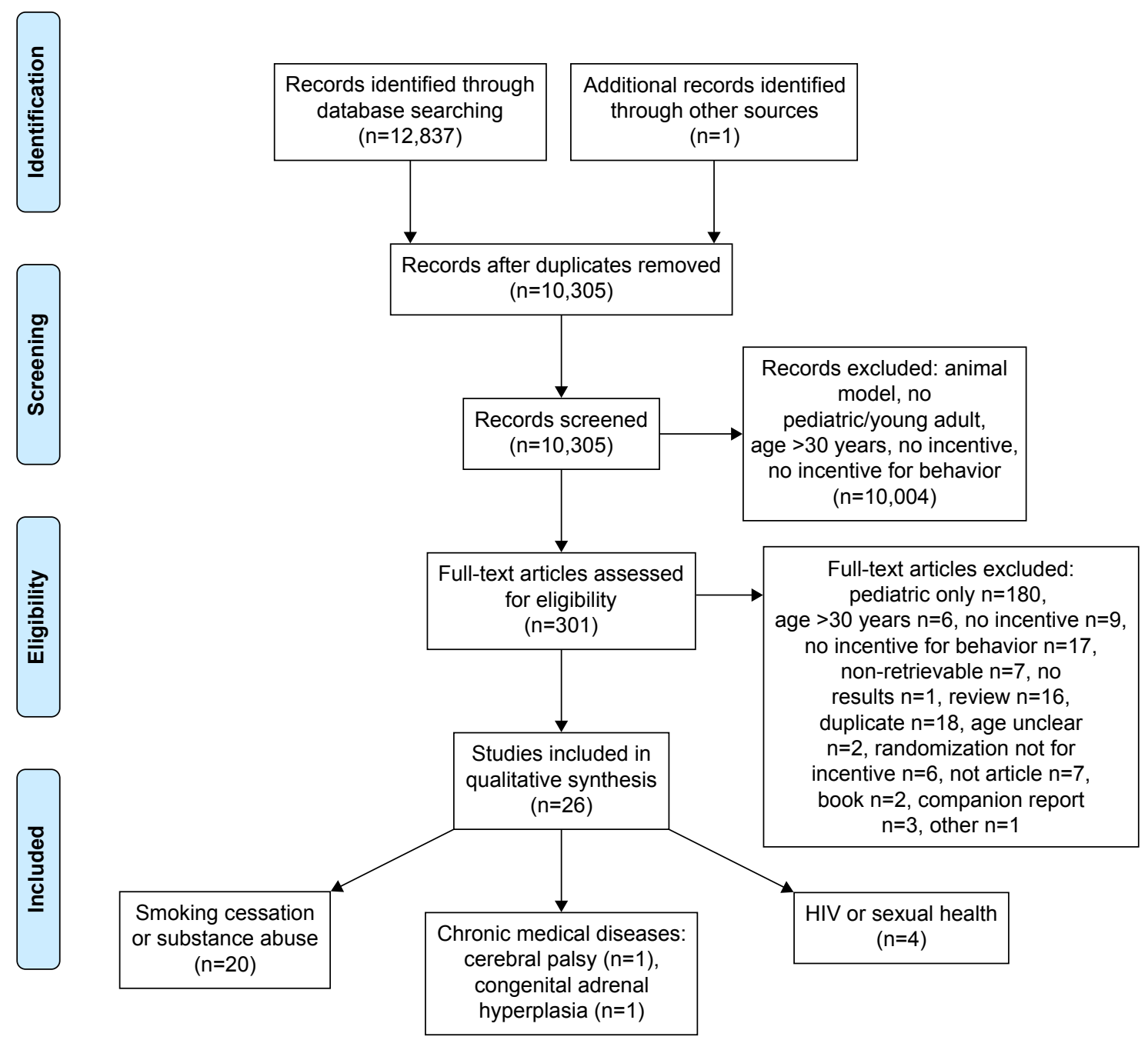

Figure I PRISMA flow diagram.

\section{Types of studies}

Fourteen articles reported the results of randomized controlled trials, , ${ }^{14,16,17,19,24-33}$ two reported the results of controlled clinical trials, ${ }^{34,35}$ one reported the results of a crossover clinical trial, ${ }^{36}$ two reported the results of cohort studies, ${ }^{6,37}$ and seven reported the results of uncontrolled before-after studies. ${ }^{15,38-43}$ Eleven of the 26 trials described the effects of behavioral interventions when conducted along with cointerventions, including motivational enhancement therapy, ${ }^{14,16,26,28,33}$ relaxation-control treatment, ${ }^{14}$ cognitive behavioral therapy, ${ }^{16,31,38}$ drug counseling, ${ }^{16}$ multidisciplinary adherence support, ${ }^{39}$ motivational interviewing, ${ }^{39}$ and instructional materials or information. ${ }^{32,40,41}$

\section{Methodological quality and risk-of-bias results}

Twelve of the 14 randomized controlled trials had a high risk of bias on at least one of the seven criteria; all randomized controlled trials had an unclear risk of bias on at least one item. Of the two controlled trials and one crossover trial, none had a high risk of bias on any item, but did have unclear risk of bias on at least one of the four applicable items. Both cohort studies had a high risk of bias on selection of cohorts and matching and assessment of prognostic factors; additionally, one study had a high risk of bias due to cointerventions.

\section{Characteristics of the target population and the behaviors incentivized}

Among the 26 articles, 20 examined the effects of behavioral incentives on cigarette smoking or substance abuse, including alcohol (cigarette smoking, $n=9$; substance abuse, $n=11$ ), four studies explored behavioral incentives in the setting of HIV or sexual health (including herpes simplex type 2 or human papilloma virus [HPV]), and two articles studied individuals with other chronic medical conditions (cerebral 
palsy and congenital adrenal hyperplasia) (Table 1). One study tested the effectiveness of an integrated cognitive behavioral and CM intervention in young people with HIV with an alcohol- and/or cannabis-use disorder, where the primary focus was on substance abuse. ${ }^{38}$ No studies were identified that specifically examined the effects of behavioral incentives among emerging adults with more commonly occurring chronic medical conditions (eg, childhood cancer, diabetes, asthma, epilepsy, or anemia). ${ }^{44}$ Sixteen articles included participants from both the pediatric $(<18$ years of age) and adult ( $\geq 18$ years of age) populations, nine articles studied individuals over the age of 18 years only, and one article studied university students ${ }^{32}$ (Table 1). The median number of study participants was 64 , with eight participants in the smallest study ${ }^{36}$ and 3,796 participants in the largest study. ${ }^{19}$

\section{Types of incentive}

The intervention types are summarized in Table 1. Eleven studies provided the incentive in the form of cash, six studies offered incentives in the form of vouchers, and nine articles described the use of a lottery scheme.

\section{Cash payments}

The value of the incentives in the eleven trials that offered cash payments varied substantially. The median total value for a cash-payment financial incentive was $\$ 120$. The lowest value was $\$ 14.40$, for a study of adolescents with congenital adrenal hyperplasia (or healthy controls) where participants could "win" up to $\$ 4.80$ in a reward-based antisaccade task (whereby one inhibits a reflexive eye movement). ${ }^{35}$ The highest total cash incentive that could be earned was $\$ 523.50$ over 3 weeks in a trial of smoking cessation. ${ }^{14}$

\section{Vouchers}

Two studies that employed vouchers were from the same group of investigators, examining the use of CM and motivation/skill-building therapy among young adults with marijuana dependence. ${ }^{16,33}$ In the primary study, participants assigned to $\mathrm{CM}$ received "vouchers redeemable for goods and services purchased by study staff'. ${ }^{16}$ Attendance at treatment sessions was rewarded with an initial voucher worth $\$ 25$, increasing in $\$ 5$ increments for each consecutive session attended. ${ }^{16}$ Participants also received $\$ 50$ for the first marijuana-free urine specimen, with increments of $\$ 5$ for each subsequent specimen received that was negative for marijuana. ${ }^{16}$ The maximum value of vouchers that could be obtained was $\$ 880$.
One study specifically employed an incentive scheme to improve medication adherence in the transitioning population. ${ }^{39}$ This article examined the effect of an incentive strategy on viral load in eleven patients with perinatally acquired HIV. Participants received gift vouchers of a value of $£ 25$ or $£ 50$ contingently on both fall in viral load and attendance for motivational interviewing. ${ }^{39}$

\section{Lottery}

Lottery incentives fell into two broad categories. Five of the studies employed an incentive strategy where participants could draw from a prize bowl if they had achieved a contingent behavior. ${ }^{17,26,28,37,38}$ As an example, in a study by Killeen et al, participants with primary marijuana-use disorder randomized to $\mathrm{CM}$ earned chances to draw from a prize bowl for provision of a negative urine drug screen in an escalating manner (number of chances increased by one per week), with a reset to zero for a positive test or an unexcused absence. ${ }^{17}$ Prize bowl-chits could be exchanged for prizes, such as phone cards, video games, iPods, iTunes vouchers, or skateboards. ${ }^{17}$

The second type of lottery approach that was employed was a "quit and win" scheme utilized by two studies of smoking cessation. ${ }^{40,42}$ In these studies, all participants who had successfully quit smoking were eligible for a prize draw. Among the other two studies that offered a lottery scheme, both involved education on alcohol awareness and offered either a reward for successfully completing a quiz or entry into a raffle for maintaining a blood-alcohol content below a set target. ${ }^{32,41}$

\section{With or without contingency management}

A total of 25 of the 26 studies offered an incentive that was contingent on behavior. Only one study reported noncontingent incentives. This was a study of HPV-vaccine uptake in young women, where vouchers were provided to enable participants to receive all three doses of the HPV vaccine at no cost. ${ }^{15}$ Thirteen studies described an escalation and reset strategy for the incentive, ${ }^{14,16,17,24,26,28,29,31-34,36,38}$ one study reported a reset scheme only, ${ }^{37}$ and 12 studies incorporated neither an escalating strategy nor a reset. ${ }^{6,15,19,25,27,30,35,39-43}$ One article reported the use of a disincentive where participants could receive a "payment reduction" from their study compensation for decreased ability to complete four cognitive/psychomotor tasks following a 3-hour ad libitum drinking period. ${ }^{27}$

\section{Studies reporting positive impact}

A total of 24 of the 26 studies reported a positive effect of the incentive strategy on either the primary or secondary 
outcome. Seventeen of these studies reported the effect as a statistically significant change $(P<0.05$ or confidence interval that did not span unity). Two reported no benefit of the intervention. ${ }^{17,29}$ The outcomes and effect sizes for each intervention varied according to disease type.

All of the nine studies of smoking cessation sought objective evidence of abstinence as a primary outcome. . $^{\text {14,24,29-31,36,40,42,43 }}$ However, the effect size differed substantially between studies. For instance in an article by An et al, 7-day abstinence rates among college smokers were 100 of 360 (38.5\%) in the control group and 152 of 257 (59.1\%) in the group assigned to a web-based intervention (adjusted odds ratio $2.43,95 \%$ confidence interval 1.70-3.48). ${ }^{30}$ By way of contrast, in a study by Tevyaw et al of non-treatment-seeking daily smokers, only three of 49 (6.1\%) participants receiving CM had verified 7-day point-prevalence abstinence vs 0 of $43(0 \%)$ in the control group, with no significant differences according to treatment allocation. ${ }^{14}$ Among the studies that evaluated incentive strategies for substance abuse, the primary outcome that was assessed reflected the heterogeneity of the study participants. As with smoking cessation, six studies sought evidence of abstinence, commonly in the form of a negative urine drug screen. ${ }^{16,17,26,33,37,38}$ Other outcomes that were assessed included vaccine-uptake rates, ${ }^{25}$ number of alcoholic beverages consumed, ${ }^{27}$ exercise frequency, ${ }^{28}$ demonstration of knowledge gained, ${ }^{41}$ blood-alcohol concentration, ${ }^{32}$ and session attendance. ${ }^{16,33,38}$ The outcomes assessed in the studies of emerging adults with cerebral palsy or congenital adrenal hyperplasia were disease- and intervention-specific (completion of frontal forearm flexor electromyography training and antisaccade accuracy). ${ }^{34,35}$

\section{Studies reporting no impact}

One randomized controlled trial reported no change in either primary or secondary outcomes in cigarette smokers at 2 -week follow-up. ${ }^{29}$ However, this was a pilot in nature, consisting of 19 participants; a subsequent trial of 110 participants by the same authors reported a reduction in CO levels and greater abstinence during the CM intervention with 6 months' follow-up. ${ }^{14}$ A separate randomized controlled trial examined the effects of a community-based CM strategy in 31 adolescents with primary marijuana-use disorder, and found that the intervention had no effect on the percentage of negative urine drug screens, sustained negative urine drug screens, or retention in treatment. ${ }^{17}$ In a third randomized controlled trial, various behavior-modification strategies were assessed in combination with bupropion SR among 134 adolescent cigarette smokers, with pooled effects indicating that CM treatment was only marginally (and insignificantly) superior to non-CM treatment. ${ }^{24}$

\section{Study reporting negative impact}

One of the articles reported negative outcomes. In this report, Corby et al described the effectiveness of CM in a cohort of eight adolescent cigarette smokers, interpreting that increasing negative mood with smoking cessation was indicative of nicotine-withdrawal syndrome. ${ }^{36}$

\section{Follow-up}

Thirteen of the 26 studies did not report a follow-up of the participants after the incentive period was terminated (Table 2). Among the 13 that did, the median duration of follow-up was 2.5 months, with the shortest study following participants up for 1-3 days ${ }^{27}$ and the longest following participants up for 12 months. ${ }^{39}$ All but two of these 13 studies reported positive outcomes; these two studies reported follow-ups of 2 weeks ${ }^{29}$ and 3 months. ${ }^{17}$

The article reporting a 12-month follow-up was the pilot study of incentives in individuals with perinatally acquired HIV. Three studies reported follow-up at 6 months after the study intervention. One of these examined the effectiveness of $\mathrm{CM}$ in young people with marijuana dependence, and found no difference between intervention strategies in the proportion of participants reporting no marijuana use in the 28 days prior to the 6-month follow-up. ${ }^{16}$ In other studies with a 6-month follow-up, the "quit and win" study by Rooney et al failed to find a reduction in cigarette smoking at 6 months, ${ }^{42}$ and rates of confirmed abstinence from cigarette smoking at 6 months were only $3.8 \%$ in a study by Tevyaw et al, with no difference according to treatment strategy. ${ }^{14}$

\section{Discussion}

Despite widespread acknowledgment of the unique challenges that emerging adults with chronic medical diseases face, there have been relatively few studies evaluating interventions aimed at easing the transition to adulthood, and fewer still that have demonstrated benefit. Cognizant of this need, we sought to determine whether literature evidence exists that behavioral incentives may be of utility in this population. By way of systematic review, we found that behavioral incentive strategies in the young adult population have been almost exclusively employed in the discouragement of the continued practice of unhealthy behaviors, such as cigarette smoking and the abuse of alcohol or marijuana. In contrast, the use of incentives to encourage the adoption 


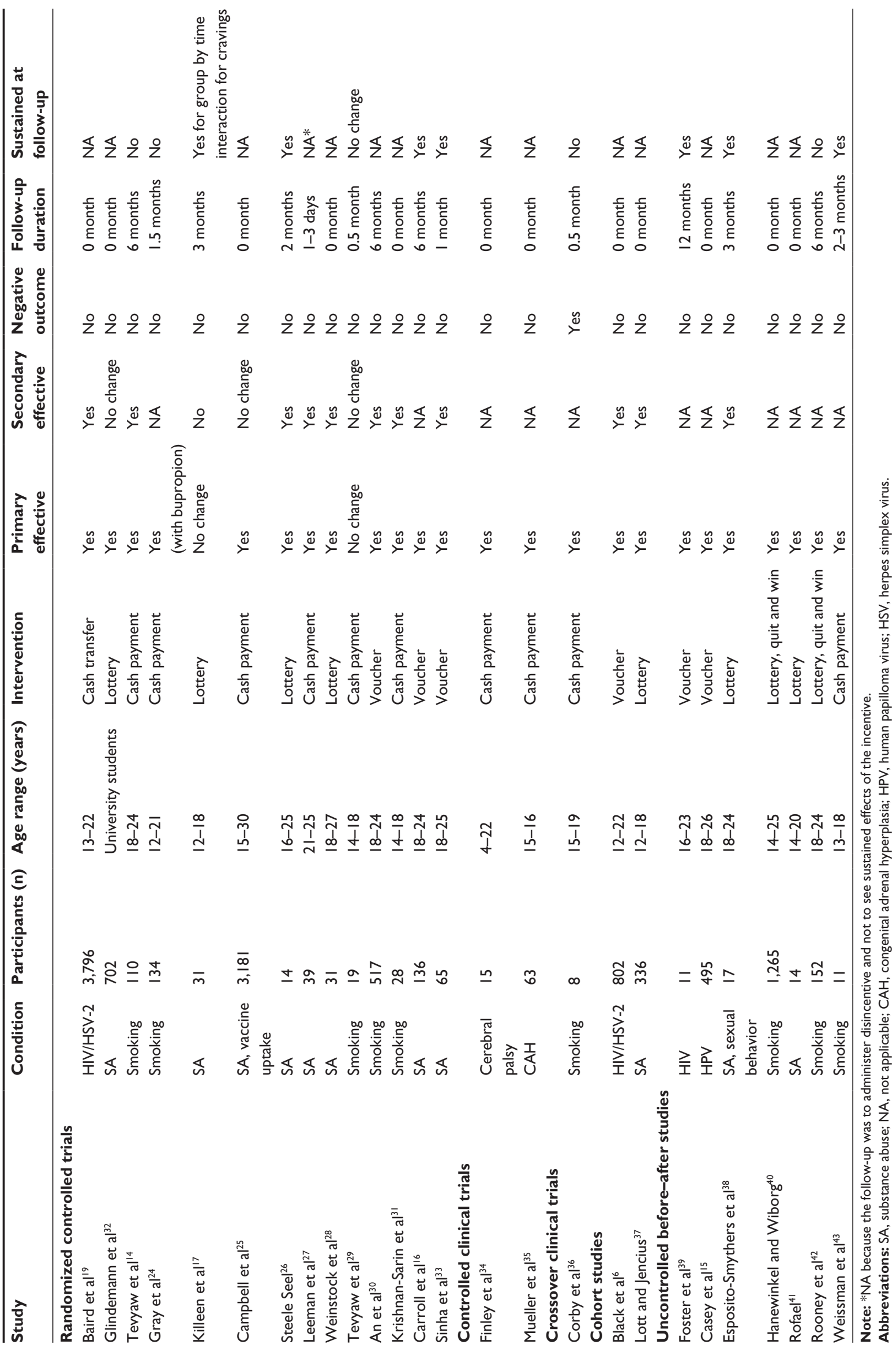


of positive self-care behaviors in young people with chronic medical conditions has been mostly overlooked. Few of the studies that did examine behavioral incentives in young adults had a low risk of bias, and few demonstrated sustained effects on long-term follow-up. Recognizing that emerging adults with chronic medical diseases face unique and distinct challenges, whether incentive strategies may have a utility in this population remains to be defined.

Illustrative of the dearth of trials evaluating interventions in young adults, in 2011 a systematic review evaluating any interventions facilitating health-related transitions in this population identified a total of only ten studies, eight of which were in young people with diabetes. ${ }^{2}$ Even in the case of diabetes, however, the majority of guideline recommendations for emerging adults are based upon expert consensus or clinical experience, and not upon randomized controlled trial evidence or meta-analyses.$^{45}$ In our review, which was conducted up to May 2014, we found no studies that had employed incentive strategies specifically in the transitioning population with diabetes. Indeed, the only study we were able to identify that sought to evaluate the use of incentives to improve medication adherence and clinic attendance was a small study of eleven individuals with perinatally acquired HIV.

In contrast to studies of young adults with chronic medical diseases, such as diabetes or HIV, we identified 20 articles reporting the effects of behavioral incentives in promoting smoking cessation or avoidance of recreational drugs or alcohol. Whereas almost all the articles we identified described a beneficial effect of the incentive strategy, fewer reported a statistically significant change, the effect sizes were very variable, and were commonly either not assessed or sustained on long-term follow-up. Lack of follow-up and durability of the effect on follow-up are common criticisms of studies of financial incentives. ${ }^{46}$

One potential negative outcome of incentive strategies in the medium to long term is the risk of "crowding out" the desired behavior, ie, a reduction in the time spent on the task, either when the reward is removed or while the incentive is still in place. Evidence supporting this concern exists in both the psychological and economic literature ${ }^{47}$ For example, in cognitive evaluation theory there are circumstances where intrinsic motivation to complete an interesting task is high, and the provision of an incentive can diminish time spent on the task once the incentive is removed. ${ }^{47}$ In behavioral economics, "motivation crowding out" has a broader definition, referring to any effect that is the opposite of the desired behavior. This opposite effect often arises when there is a conflict of interest between the incentivizing and incentivized parties. ${ }^{47}$ There are, however, several characteristics of health behaviors that suggest that the effects of crowding out may be different or unapparent when incentivizing health choices. For example, in most cases the intrinsic motivation to adopt the desired health behavior is generally low, and an interpersonal conflict is often unapparent. ${ }^{47}$ Furthermore, many detrimental health-related behaviors can be perceived as problems of self-control, and an incentive may provide a temporal bridge between immediate benefit and long-term health benefit. At the present time at least, there is an absence of evidence in the literature supporting a prominent effect of crowding out phenomena undermining the effects of incentives for health-related behaviors. ${ }^{47}$

In most of the articles identified through our systematic review, interventions were designed to assist an individual in "breaking bad habits". In this setting, behavioral incentives usually take the form of conventional CM approaches, where a reward is provided contingently on the objective demonstration of cessation of the behavior and withdrawn when the behavior is readopted. From a societal perspective, incentive strategies under these circumstances have come under criticism for unfairly rewarding "bad behavior", ${ }^{5}$ likely contributing to the perceived relative unacceptability of financial incentives compared to other interventions of theoretically equal efficacy. ${ }^{48}$ In contrast, it is possible that the use of incentives to encourage "good behaviors" (eg, self-monitoring of blood glucose in people with diabetes) may be deemed more acceptable. ${ }^{48}$ Similarly, the response to the incentive under these circumstances may be distinct, and cannot necessarily be predicted from that in the cigarette-smoking/substance-abuse setting. Unfortunately, we found few studies that addressed the use of incentives to promote the adoption of healthy behavior choices that extended beyond those expected of the population in general. In contrast, a systematic review of incentives in the adult population identified 34 relevant trials, with 19 focused on smoking cessation and 15 on healthier eating or physical activity; it found that incentives could change health-related behavior, but effects were short-lived. ${ }^{49}$ That being said, it is noteworthy that a recent article published online in 2015 found that providing monetary reinforcers (\$0.10/test) increased the frequency of blood-glucose testing in ten adolescents over a 12 -week period..$^{50}$ Whether these positive behaviors can be sustained and be replicated in a larger patient cohort remains to be seen.

In considering the reasons affecting the "acceptability" of financial incentives in the health care setting, it has been recognized that the transfer of cash or an equivalent between health care provider and receiver may be viewed as breaching a cultural norm. ${ }^{48,51}$ Therefore, provision of the 
incentive in the form of a voucher rather than cash may be more acceptable. ${ }^{48}$ In the present review, approximately even numbers of studies offered the reward as cash and as vouchers. A competitive or chance element to reward provision was also commonly employed. In terms of the value of the rewards, a previous study of prize reinforcement in cocaine users noted superior outcomes with an expected maximum reinforcement of $\$ 240$ compared to $\$ 80,{ }^{52}$ whereas the median cash payment in the present review was $\$ 120$, with only three studies exceeding $\$ 240 .^{14,24,31}$ Conflicting meta-analyses have described both a positive and negative relationship between the value of the incentive and its efficacy. ${ }^{46}$

Our study had limitations. With the desire to examine the use of incentive strategies in individuals with chronic medical conditions, we elected not to study their role in weight management. Our initial search was conducted 1 week before obesity was declared a disease by the American Medical Association, ${ }^{10}$ and even now such a designation remains controversial.$^{53} \mathrm{~A}$ recent systematic review pointed toward the positive association between incentives and dietary behavior change in the short term. ${ }^{54}$ However, a separate meta-analysis of weight-loss trials with a follow-up of at least 1 year or more showed no benefit of incentives. ${ }^{55}$ Interestingly, another systematic review and meta-analysis set out to examine the effects of incentive strategies specifically on behavior in "freeliving 'healthy' adults" by focusing on the nonclinical adult population, ${ }^{46}$ identifying 17 papers (reporting on 16 studies), with no overlap with the present review. ${ }^{46}$ In that review, there were ten studies of smoking cessation, five of attendance for vaccination or screening, and one of physical activity, with meta-analyses revealing a positive effect of incentives over both the short ( $\leq 6$ months) and longer ( $>6$ months) term and with some indication of a waning of effect size over time. In the present review, we focused on identifying the types of incentive strategies employed in the emerging adult population and the medical conditions in which they had been assessed, rather than outcomes, appreciating at the outset that: 1) a disparate set of outcome measures would preclude metaanalysis, and 2) even if a strategy had demonstrated benefit during the period of study, its durability on follow-up may not have been demonstrated or even studied.

\section{Conclusion}

In summary, although health care providers readily recognize the difficulties emerging adults with chronic medical conditions face, few studies have been undertaken that address these challenges. Behavioral incentives have been employed with short-term benefit in other patient groups. In the emerging adult population, these strategies have been most extensively studied in the context of the discouragement of cigarette smoking or marijuana use. The assimilation of study characteristics herein described may inform ongoing and future clinical trials to determine whether such an approach may play any role in the medical management of emerging adults with chronic medical conditions.

\section{Acknowledgments}

The authors thank Ms Laure Perrier for performing the literature search. GG was supported by a Charles Hollenberg Summer Studentship from the Banting and Best Diabetes Centre, University of Toronto. Dr Siddiqi was supported by a Banting and Best Diabetes Centre Fellowship in Diabetes Care (funded by Eli Lilly Canada).

Study manuals are available by request to the corresponding author.

\section{Disclosure}

The authors report no conflicts of interest in this work.

\section{References}

1. Arnett JJ. Emerging adulthood. A theory of development from the late teens through the twenties. Am Psychol. 2000;55(5):469-480.

2. Crowley R, Wolfe I, Lock K, McKee M. Improving the transition between paediatric and adult healthcare: a systematic review. Arch Dis Child. 2011;96(6):548-553.

3. Gorter JW, Stewart D, Cohen E, et al. Are two youth-focused interventions sufficient to empower youth with chronic health conditions in their transition to adult healthcare: a mixed-methods longitudinal prospective cohort study. BMJ Open. 2015;5(5):e007553.

4. Michie S, Richardson M, Johnston M, et al. The behavior change technique taxonomy (v1) of 93 hierarchically clustered techniques: building an international consensus for the reporting of behavior change interventions. Ann Behav Med. 2013;46(1):81-95.

5. Marteau TM, Ashcroft RE, Oliver A. Using financial incentives to achieve healthy behaviour. BMJ. 2009;338:b1415.

6. Black S, Wallace M, Middelkoop K, et al. Improving HIV testing amongst adolescents through and integrated Youth Centre rewards program: insights from South Africa. Child Youth Ser Rev. 2014;45: 98-105.

7. Prendergast M, Podus D, Finney J, Greenwell L, Roll J. Contingency management for treatment of substance use disorders: a meta-analysis Addiction. 2006;101(11):1546-1560.

8. Cahill K, Hartmann-Boyce J, Perera R. Incentives for smoking cessation. Cochrane Database Syst Rev. 2015;5:CD004307.

9. Moher D, Liberati A, Tetzlaff J, Altman DG. Preferred reporting items for systematic reviews and meta-analyses: the PRISMA statement. PLoS Med. 2009;6(7):e1000097.

10. AMA House of Delegates. Resolution 420. Recognition of Obesity as a Disease. Available from: http://www.npr.org/documents/2013/jun/amaresolution-obesity.pdf. Accessed March 10, 2016.

11. Rudolph C, Rudolph A, Lister G, First L, Gershon A. Rudolph's Pediatrics. 22nd ed. New York: McGraw-Hill Education; 2011.

12. McLellan AT, Lewis DC, O'Brien CP, Kleber HD. Drug dependence, a chronic medical illness: implications for treatment, insurance, and outcomes evaluation. JAMA. 2000;284(13):1689-1695.

13. American Psychiatric Association. Diagnostic and Statistical Manual of Mental Disorders. 5th ed. Washington: APA; 2013. 
14. Tevyaw TO, Colby SM, Tidey JW, et al. Contingency management and motivational enhancement: a randomized clinical trial for college student smokers. Nicotine Tob Res. 2009;11(6):739-749.

15. Casey BR, Crosby RA, Vanderpool RC, Dignan M, Bates W. Predictors of initial uptake of human papillomavirus vaccine uptake among rural Appalachian young women. J Prim Prev. 2013;34(1-2):71-80.

16. Carroll KM, Easton CJ, Nich C, et al. The use of contingency management and motivational/skills-building therapy to treat young adults with marijuana dependence. J Consult Clin Psychol. 2006;74(5):955-966.

17. Killeen TK, McRae-Clark AL, Waldrop AE, Upadhyaya H, Brady KT. Contingency management in community programs treating adolescent substance abuse: a feasibility study. J Child Adolesc Psychiatr Nurs. 2012;25(1):33-41.

18. John LK, Loewenstein G, Troxel AB, Norton L, Fassbender JE, Volpp KG. Financial incentives for extended weight loss: a randomized, controlled trial. J Gen Intern Med. 2011;26(6):621-626.

19. Baird SJ, Garfein RS, McIntosh CT, Ozler B. Effect of a cash transfer programme for schooling on prevalence of HIV and herpes simplex type 2 in Malawi: a cluster randomised trial. Lancet. 2012;379(9823): $1320-1329$.

20. Higgins JP, Altman DG, Gotzsche PC, et al. The Cochrane Collaboration's tool for assessing risk of bias in randomised trials. BMJ. 2011;343:d5928.

21. Montgomery L, Petry NM, Carroll KM. Moderating effects of race in clinical trial participation and outcomes among marijuana-dependent young adults. Drug Alcohol Depend. 2012;126(3):333-339.

22. Vanderpool RC, Casey BR, Crosby RA. HPV-related risk perceptions and HPV vaccine uptake among a sample of young rural women. J Community Health. 2011;36(6):903-909.

23. Easton CJ, Oberleitner LM, Scott MC, Crowley MJ, Babuscio TA, Carroll KM. Differences in treatment outcome among marijuanadependent young adults with and without antisocial personality disorder. Am J Drug Alcohol Abuse. 2012;38(4):305-313.

24. Gray KM, Carpenter MJ, Baker NL, et al. Bupropion SR and contingency management for adolescent smoking cessation. J Subst Abuse Treat. 2011;40(1):77-86.

25. Campbell JV, Garfein RS, Thiede H, et al. Convenience is the key to hepatitis A and B vaccination uptake among young adult injection drug users. Drug Alcohol Depend. 2007;91 Suppl 1:S64-S72.

26. Steele Seel JM. Eliciting abstinence and improving retention in a vocational and educational training program for young people: a pilot study [dissertation]. Albuquerque: University of New Mexico; 2011.

27. Leeman RF, Corbin WR, Nogueira C, Krishnan-Sarin S, Potenza MN, O'Malley SS. A human alcohol self-administration paradigm to model individual differences in impaired control over alcohol use. Exp Clin Psychopharmacol. 2013;21(4):303-314.

28. Weinstock J, Capizzi J, Weber SM, Pescatello LS, Petry NM. Exercise as an intervention for sedentary hazardous drinking college students: a pilot study. Ment Health Phys Act. 2014;7(1):55-62.

29. Tevyaw TO, Gwaltney C, Tidey J, et al. Contingency management for adolescent smokers: an exploratory study. J Child Adolesc Subst Abuse. 2007;16(4):23-44.

30. An LC, Klatt C, Perry CL, et al. The RealU online cessation intervention for college smokers: a randomized controlled trial. Prevent Med. 2008;47(2):194-199.

31. Krishnan-Sarin S, Duhig AM, McKee SA, et al. Contingency management for smoking cessation in adolescent smokers. Exp Clin Psychopharmacol. 2006;14(3):306-310.

32. Glindemann KE, Ehrhart IJ, Drake EA, Geller ES. Reducing excessive alcohol consumption at university fraternity parties: a cost-effective incentive/reward intervention. Addict Behav. 2007;32(1):39-48.

33. Sinha R, Easton C, Renee-Aubin L, Carroll KM. Engaging young probation-referred marijuana-abusing individuals in treatment: a pilot trial. Am J Addict. 2003;12(4):314-323.

34. Finley WW, Etherton MD, Dickman D, Karimian D, Simpson RW. A simple EMG-reward system for biofeedback training of children. Biofeedback Self Regul. 1981;6(2):169-180.
35. Mueller SC, Daniele T, MacIntyre J, et al. Incentive processing in congenital adrenal hyperplasia $(\mathrm{CAH})$ : a reward-based antisaccade study. Psychoneuroendocrinology. 2013;38(5):716-721.

36. Corby EA, Roll JM, Ledgerwood DM, Schuster CR. Contingency management interventions for treating the substance abuse of adolescents: a feasibility study. Exp Clin Psychopharmacol. 2000;8(3):371-376.

37. Lott DC, Jencius S. Effectiveness of very low-cost contingency management in a community adolescent treatment program. Drug Alcohol Depend. 2009;102(1-3):162-165.

38. Esposito-Smythers C, Brown LK, Wolff J, et al. Substance abuse treatment for HIV infected young people: an open pilot trial. J Subst Abuse Treat. 2014;46(2):244-250.

39. Foster C, McDonald S, Frize G, Ayers S, Fidler S. "Payment by results"-financial incentives and motivational interviewing, adherence interventions in young adults with perinatally acquired HIV-1 infection: a pilot program. AIDS Patient Care STDS. 2014;28(1):28-32.

40. Hanewinkel R, Wiborg G. Initial evaluation of a real-world self-help smoking cessation programme for adolescents and young adults. Addict Behav. 2006;31(10):1939-1945.

41. Rofael M. Splat - when alcohol and cars collide: increasing awareness of high school athletes about the dangers of drinking and driving. J Investig Med. 2013;61(1):158.

42. Rooney BL, Silha P, Gloyd J, Kreutz R. Quit and Win smoking cessation contest for Wisconsin college students. WMJ. 2005;104(4):45-49.

43. Weissman W, Glasgow R, Biglan A, Lichtenstein E. Development and preliminary evaluation of a cessation program for adolescent smokers. Psychol Addict Behav. 1987;1(2):84-91.

44. Compas BE, Jaser SS, Dunn MJ, Rodriguez EM. Coping with chronic illness in childhood and adolescence. Annu Rev Clin Psychol. 2012;8:455-480.

45. Peters A, Laffel L. Diabetes care for emerging adults: recommendations for transition from pediatric to adult diabetes care systems. Diabetes Care. 2011;34(11):2477-2485.

46. Giles EL, Robalino S, McColl E, Sniehotta FF, Adams J. The effectiveness of financial incentives for health behaviour change: systematic review and meta-analysis. PLoS One. 2014;9(3):e90347.

47. Promberger M, Marteau TM. When do financial incentives reduce intrinsic motivation? Comparing behaviors studied in psychological and economic literatures. Health Psychol. 2013;32(9):950-957.

48. Promberger M, Brown RC, Ashcroft RE, Marteau TM. Acceptability of financial incentives to improve health outcomes in UK and US samples. J Med Ethics. 2011;37(11):682-687.

49. Mantzari E, Vogt F, Shemilt I, Wei Y, Higgins JP, Marteau TM. Personal financial incentives for changing habitual health-related behaviors: a systematic review and meta-analysis. Prev Med. 2015;75:75-85.

50. Petry N, Cengiz E, Wager J, Weyman K, Tichy E, Tamborlane WV. Testing for rewards: a pilot study to improve type 1 diabetes management in adolescents. Diabetes Care. 2015;38(10):1952-1954.

51. Hoddinott P, Morgan H, MacLennan G, et al. Public acceptability of financial incentives for smoking cessation in pregnancy and breast feeding: a survey of the British public. BMJ Open. 2014;4(7):e005524.

52. Petry NM, Tedford J, Austin M, Nich C, Carroll KM, Rounsaville BJ. Prize reinforcement contingency management for treating cocaine users: how low can we go, and with whom? Addiction. 2004;99(3): 349-360.

53. Katz DL. Perspective: obesity is not a disease. Nature. 2014; 508(7496):S57.

54. Purnell JQ, Gernes R, Stein R, Sherraden MS, Knoblock-Hahn A. A systematic review of financial incentives for dietary behavior change. J Acad Nutr Diet. 2014;114(7):1023-1035.

55. Paul-Ebhohimhen V, Avenell A. Systematic review of the use of financial incentives in treatments for obesity and overweight. Obes Rev. 2008;9(4):355-367. 
Patient Preference and Adherence

Dovepress

\section{Publish your work in this journal}

Patient Preference and Adherence is an international, peer-reviewed, open access journal that focuses on the growing importance of patient preference and adherence throughout the therapeutic continuum. Patient satisfaction, acceptability, quality of life, compliance, persistence and their role in developing new therapeutic modalities and compounds to optimize

Submit your manuscript here: http://www.dovepress.com/patient-preference-and-adherence-journ clinical outcomes for existing disease states are major areas of interest for the journal. This journal has been accepted for indexing on PubMed Central The manuscript management system is completely online and includes a very quick and fair peer-review system, which is all easy to use. Visit http://www. dovepress.com/testimonials.php to read real quotes from published authors. 